\title{
Editorial: Modeling the Plankton-Enhancing the Integration of Biological Knowledge and Mechanistic Understanding
}

\author{
Christian Lindemann ${ }^{1 *}$, Dag L. Aksnes ${ }^{1}$, Kevin J. Flynn ${ }^{2}$ and Susanne Menden-Deuer ${ }^{3}$ \\ ${ }^{1}$ Department of Biology, University of Bergen, Bergen, Norway, ${ }^{2}$ Department of Biosciences, Swansea University, Swansea, \\ United Kingdom, ${ }^{3}$ Graduate School of Oceanography, University of Rhode Island, Narragansett, RI, United States
}

Keywords: planktonic food web, ecosystem, biogeochemistry, functional diversity, Climate change simulation

\section{Editorial on the Research Topic}

Modeling the Plankton-Enhancing the Integration of Biological Knowledge and Mechanistic Understanding

In marine science numerical models, and especially ecosystem models, have developed into an important tool for policy advice and environmental management applications (Rose et al., 2010; Holt et al., 2014; Robson, 2014; Lynam et al., 2016). The predictive capabilities of these models, in particular under changing environmental conditions, naturally rely strongly on the model formulation, including choice of functional groups and the form of their representation, i.e., their parameterisation.

In recent years, new knowledge generated regarding organism physiology; ecosystem functioning; new data types and increased resolution of data acquisition, particularly those collected by satellites, autonomous platforms and through genetic analyses; as well as new approaches to model marine systems have emerged, altering the way we think about modeling the plankton.

Mechanistic descriptions which can reflect physiological, behavioral and life-history traits

OPEN ACCESS

Edited and reviewed by: Angel Borja,

AZTI Pasaia, Spain

*Correspondence:

Christian Lindemann chris.lindemann@uib.no

Specialty section:

This article was submitted to Marine Ecosystem Ecology,

a section of the journal

Frontiers in Marine Science

Received: 13 October 2017 Accepted: 25 October 2017 Published: 07 November 2017

Citation:

Lindemann C, Aksnes DL, Flynn KJ and Menden-Deuer S (2017) Editorial: Modeling the Plankton-Enhancing the Integration of Biological Knowledge and Mechanistic Understanding. Front. Mar. Sci. 4:358. doi: 10.3389/fmars.2017.00358 (Baklouti et al., 2006), can improve the individual representation and thus provide a more robust platform, valid for a wider range of circumstances. Trait-based modeling and size-based scaling approaches have emerged as fruitful approaches, in some marine systems, to categorizes biological entities by their ecological meaningful characteristic (Litchman and Klausmeier, 2008). This can be done by using certain defining characteristics, such as cell size (Andersen et al., 2016), to scale related processes and functions.

Papers in this research topic provide insights into novel developments in the representation of plankton groups and how these improvements affect model outcomes. The scope of articles covers a wide range of different aspects, from viruses to fish larvae, from single cell mechanisms to improved description of community structure, from purely theoretical approaches to data heavy applications.

Though viruses have been recognized as an important player in the marine food web (Suttle, 2005) their inclusion in models remains rare. In a combination of review and modeling study, Record et al., assess key characteristics of marine viruses and the trade-offs between lysogenic and lytic strategies, particularly as a function of nutrient inputs to the system.

Similarly the ability of many phytoplankton and microzooplankton species to be mixotrophic, which has been known for decades with some attempts made to provide a conceptual basis for models (reviewed by Stoecker, 1998), is only now becoming mainstream. Ghyoot et al. tackle the challenge of modeling mixotrophy, proposing modifications to one of the classic approaches to modeling plankton, the Shuter approach (Shuter, 1979), that enables the simulation of the two main groups of mixotrophs, namely of the constitutives ("phytoplankton that eat") and non-constitutives ("microzooplankton that photosynthesizes") growing in the North Sea.

Using bulk nutrient uptake observations in combination with allometric scaling predictions, Atkins et al. suggest that net nitrogen dynamics can be quantified at an assemblage 
scale using size dependencies of Michaelis-Menten uptake parameters and that their method can be applied to particle size distributions that have been routinely measured in eutrophic systems.

Exploiting a statistical approach, Stawiarski et al. compare different strains of picokaryotes in relation to Eppley's empirical relationships of temperature dependent growth (Eppley, 1972). Their results indicate that, when compared to picoeukaryotes, prokaryotic picoplankton have lower growth temperatures and a narrower temperature range. Interestingly they also find that the temperature tolerance range follows a unimodal function of cell size, with the $\mathrm{Q}_{10}$ values for picoeukaryotes and picoprokaryotes being 2.3 and of 4.9 , respectivly.

Sourisseau et al. explore the usefulness of a trait-tradeoff approach to help improve descriptions of the success of the harmful algae bloom dinoflagellate Alexandrium minutum under conditions of changing temperature and the hydrographic conditions of the estuary.

Based on recent experimental data published on evolutionary change in a coccolithophore, Denman provides evidence that genetic mutations alone do not suffice to explain rapid thermal adaptation. This study contributes significant new knowledge to the field of organismal adaptation in the face of global warming.

Satellites have long been an important tool in oceanography as their measurement capacity is uniquely suited to transcend the large spatial scales of the global and dynamic ocean. Gregg and Rousseaux incorporate key characteristics of radiative transfer into a biogeochemical model and identified quantifiable trade-offs between nutrient concentration, phytoplankton type and directionality and attenuation wavelength that could affect net primary production and chlorophyll-a concentration from negligible to over $25 \%$.

Laiolo et al. examine the seasonal plankton dynamics of cyclonic and anticyclonic eddies using satellite data, in situ observations and assimilating chlorophyll-a data into biogeochemical models of different complexity. Due to the shallower mixed layer, model simulations of cyclonic eddies show higher chlorophyll-a concentrations and higher concentration of large phytoplankton driven by higher light availability due to the mixed layer shoaling.

Increasing data and information use have been suggested as a step toward improving management applications (Dyble et al., 2008; Lynam et al., 2016). Everett et al. present a review on the current practices in zooplankton observation and modeling. They detail two ways that zooplankton biomass/abundance observations can be used to assess models: data wrangling that transforms observations to be more similar to model output; and observation models that transform model outputs to be more like observations.

Resolving zooplankton feeding traits to a sufficient degree can provide important insights into zooplankton dynamics and the dynamics of marine ecosystems. Wilson et al. use a trait-structured modeling approach to understand possible causes of differences between the C. finmarchicus and C. helgolandicus biogeographies. Based on their analyses they hypothesize that food quality is a key influence on the population dynamics and distribution of the two species.
Dufour et al. quantified intra-guild predation on copepod eggs by two dominant arctic species, Calanus hyperboreus and Metridia longa as a function of temperature, egg and alternative prey concentration. Incorporating these remarkably variable empirical data in a model simulation showed that $M$. longa predation had minimal impact on $C$. hyperboreus recruitment, but did benefit $M$. longa's metabolic demands.

In size-spectrum models smaller zooplankton are often lumped together with phytoplankton, whereas larger (meso) zooplankton are categorized as fish. In the study by Heneghan et al. resolving zooplankton feeding traits explicitly led to an overall increase in fish biomass but also to a tradeoff between productivity and stability. While herbivorous zooplankton supported more productive fish communities with higher resilience to fishing pressure, carnivorous zooplankton had a stabilzing effect on fish communities.

Life history can play an important role in the survival strategy of marine plankton, nevertheless it is often ignored in marine ecosystem models (Rose et al., 2010). Exemplified with species of the Calanus genus, Banas et al. modeled copepod life history traits and adaptation in seasonal environments. Their modeling experiments demonstrate that patterns in copepod community composition and productivity may be predicted from only a few key constraints on the individual energy budget.

Coupling ocean circulation models with Individual-BasedModels, Mayorga-Adame et al. investigated the effects of larval life-history on the connectivity of different organisms in between east African coral reefs. Long pelagic larval duration with active migration abilities, such as fish, had a much higher settling probability $(>20 \%)$ than passive species like coral larvae $(<1 \%)$.

Clearly, this research topic has attracted a varied range of modeling types, investigating functionally diverse organisms and probing a multitude of processes, from individual life histories to ecosystem nutrient dynamics and biophysical interactions driving the abundance, distribution and ultimately the biogeochemical footprint of plankton. Our ability to model key processes in plankton ecology and oceanography still lags behind the highly species-specific physiologies and behaviors of phylogenetically diverse plankton in a dynamic ocean (Menden-Deuer and Kiørboe, 2016). The contributions compiled here take important steps forward in demonstrating how modeling plankton yields important insights. Moreover, this compilation hopefully inspires others to integrate their empirical and analytical approaches with modeling, for equally fruitful outcomes.

\section{AUTHOR CONTRIBUTIONS}

All authors wrote a summary for the articles they edited. CL wrote the initial draft of the editorial. All editors commented on the editorial.

\section{FUNDING}

SM received support from the National Science Foundation Biological-Oceanography award 1736635. 


\section{REFERENCES}

Andersen, K. H., Berge, T., Gonçalves, R. J., Hartvig, M., Heuschele, J., Hylander, S., et al. (2016). Characteristic sizes of life in the Oceans, from Bacteria to Whales. Annu. Rev. Mar. Sci. 8, 217-241. doi: 10.1146/annurev-marine-122414-0 34144

Baklouti, M., Diaz, F., Pinazo, C., Faure, V., and Quéguiner, B. (2006). Investigation of mechanistic formulations depicting phytoplankton dynamics for models of marine pelagic ecosystems and description of a new model. Progr. Oceanogr. 71,1-33. doi: 10.1016/j.pocean.2006.05.002

Dyble, J., Bienfang, P., Dusek, E., Hitchcock, G., Holland, F., Laws, E., et al. (2008). Environmental controls, oceanography and population dynamics of pathogens and harmful algal blooms: connecting sources to human exposure. Environ. Health 7(Suppl 2):S5. doi: 10.1186/1476-069 $\mathrm{X}-7-\mathrm{S} 2-\mathrm{S} 5$

Eppley, R. W. (1972). Temperature and Phytoplankton Growth in the Sea. Fish. Bullet. 70, 1063-1085.

Holt, J., Allen, J. I., Anderson, T. R., Brewin, R., Butenschön, M., Harle, J., et al. (2014). Challenges in integrative approaches to modelling the marine ecosystems of the North Atlantic: physics to fish and coasts to ocean. Progr. Oceanogr. 129, 285-313. doi: 10.1016/j.pocean.2014.04.024

Litchman, E., and Klausmeier, C. A. (2008). Trait-based community ecology of phytoplankton. Annu. Rev. Ecol. Evol. Syst. 39, 615-639. doi: 10.1146/annurev.ecolsys.39.110707.173549

Lynam, C. P., Uusitalo, L., Patrício, J., Piroddi, C., Queirós, A. M., Teixeira, H., et al. (2016). Uses of Innovative Modeling Tools within the Implementation of the Marine Strategy Framework Directive. Front. Marine Sci. 3:182. doi: $10.3389 /$ fmars.2016.00182
Menden-Deuer, S., and Kiørboe, T. (2016). Small bugs with a big impact : linking plankton ecology with ecosystem processes. J. Plankton Res. 38, 1036-1043. doi: 10.1093/plankt/fbw049

Robson, B. J. (2014). When do aquatic systems models provide useful predictions, what is changing, and what is next? Environ. Model. Softw. 61, 287-296. doi: 10.1016/j.envsoft.2014.01.009

Rose, K. A., Allen, J. I., Artioli, Y., Barange, M., Blackford, J., Carlotti, F., et al. (2010). End-to-end models for the analysis of marine ecosystems: challenges, issues, and next steps. Marine Coast. Fish. 2, 115-130. doi: 10.1577/C09-059.1

Shuter, B. (1979). A model of physiological adaptation in unicellular algae. J. Theor. Biol. 78, 519-552. doi: 10.1016/0022-5193(79)90189-9

Stoecker, D. K. (1998). Conceptual models of mixotrophy in planktonic protists and some ecological and evolutionary implications. Eur. J. Protistol. 34, 281-290. doi: 10.1016/S0932-4739(98)80055-2

Suttle, C. A. (2005). Viruses in the Sea. Nature 437, 356-361. doi: 10.1038 /nature04160

Conflict of Interest Statement: The authors declare that the research was conducted in the absence of any commercial or financial relationships that could be construed as a potential conflict of interest.

Copyright (c) 2017 Lindemann, Aksnes, Flynn and Menden-Deuer. This is an openaccess article distributed under the terms of the Creative Commons Attribution License (CC BY). The use, distribution or reproduction in other forums is permitted, provided the original author(s) or licensor are credited and that the original publication in this journal is cited, in accordance with accepted academic practice. No use, distribution or reproduction is permitted which does not comply with these terms. 